\title{
A Theoretical $F$ Region Study of Ion Compositional and Temperature Variations in Response to Magnetospheric Storm Inputs
}

\author{
J. J. SOJKA AND R. W. SCHUNK \\ Center for Atmospheric and Space Sciences, Utah State University
}

\begin{abstract}
The response of the polar ionosphere to magnetospheric storm inputs was modeled. During the "storm," the spatial extent of the auroral oval, the intensity of the precipitating auroral electron energy flux, and the plasma convection pattern were varied with time. The convection pattern changed from a symmetric two-cell pattern with a $20-\mathrm{kV}$ cross-tail potential to an asymmetric two-cell pattern with enhanced plasma flow in the dusk sector and a total cross-tail potential of $90 \mathrm{kV}$. During the storm there were significant changes in the ion temperature, ion composition, and molecular/atomic ion transition height. The storm time asymmetric convection pattern produced an ion temperature hot spot at the location of the dusk convection cell owing to increased ion-neutral frictional heating. In this hot spot there were significantly enhanced $\mathrm{NO}^{+}$densities and hence molecular/atomic ion transition heights. During the storm recovery phase, the decay of the enhanced $\mathrm{NO}^{+}$densities closely followed the decrease in the plasma convection speed. During the storm, elevated ion temperatures also appeared at high altitudes in the midnight-dawn auroral oval region. These elevated ion temperatures were a consequence of the storm-enhanced topside $\mathrm{O}^{+}$densities, which provided better thermal coupling to the hot electrons. This region also contained reduced molecular/atomic ion transition heights. These elevated ion temperatures and reduced transition heights persisted for several hours after the storm main phase ended.
\end{abstract}

\section{INTRODUCTION}

During the past few years, we have developed a comprehensive model of the convecting high-latitude ionosphere in order to determine the extent to which various chemical and transport processes affect the ion composition and electron density at $F$ region altitudes [cf. Schunk and Raitt, 1980; Sojka et al, 1981a, b; Schunk and Sojka, 1982a]. Our numerical model produces time-dependent, three-dimensional ion density distributions for the ions $\mathrm{NO}^{+}, \mathrm{O}_{2}^{+}, \mathrm{N}_{2}^{+}, \mathrm{O}^{+}, \mathrm{N}^{+}$, and $\mathrm{He}^{+}$. The model takes account of diffusion, thermospheric winds, electrodynamic drifts, polar wind escape, energy dependent chemical reactions, magnetic storm induced neutral composition changes, and ion production due to solar EUV radiation and energetic particle precipitation.

In an initial application of this model, we studied the high-latitude $F$ region for winter, solar minimum, and low geomagnetic activity conditions [Sojka et al, 1981a, b]. In a subsequent study [Sojka et al, 1981c], we compared the response of the winter $F$ region to both weak and strong plasma convection. For strong convection, we also studied the seasonal variations of the high-latitude ionosphere [Sojka et al, 1982]. One of the important results that emerged from these studies was that high-latitude ionospheric features, such as the "main trough," the "ionization hole," the "tongue of ionization," and the "aurorally produced ionization peaks," are a natural consequence of the competition between the various chemical and transport processes known to be operating in the high-latitude ionosphere. We also found that these features display a marked variation with season, convection pattern, and universal time (UT).

In the studies described above, the cross-tail magneto-

\section{Copyright 1984 by the American Geophysical Union.}

Paper number 4A0053.

0148-0227/84/004A-0053\$05.00 spheric electric potential was assumed to be constant, and the time-dependence was a consequence of the relative motion between the geomagnetic and geographic poles. As the plasma convection pattern rotates about the geographic pole, the high-latitude ionosphere moves toward and then away from the sun, producing a UT variation in the photoionization rate. In our first storm study [Sojka and Schunk, 1983], we considered a more com plicated time-dependent situation in that we modeled the response of the high latitude $F$ region to magnetospheric storm inputs. The magnetospheric storm inputs that we varied were the extent of the auroral oval, the precip itating electron energy flux, and the plasma convection pattern. From that study we found that the $F$ region has markedly different characteristics at different altitudes; at low altitudes $(\leqslant 200 \mathrm{~km})$, chemistry dominates and consequently chemical time constants (seconds to a few minutes) characterized the $N_{e}$ variations. However, at $h_{m} F_{2}$ and above, diffusion was important and time scales of tens of minutes to hours was characteristic. As \& result, the bottomside morphology of $N_{e}$ was in phase with the storm inputs, while the topside $N_{e}$ morphology showed no relationship to the storm inputs and lagged these input variations by up to 5 hours in high-altitude regions. In this study we consider the variations of the $F$ region ion composition and ion temperature for the same storm conditions used in our previous storm study [Sojka and Schunk, 1983].

\section{STORM-DEPENDENT IONOSPHERIC MODEL}

The complete description of our high-latitude ionospheric model is given elsewhere [Schunk and Raitt, 1980; Sojka et al, 1981a, b; Schunk and Sojka, 1982a], while \& detailed description of the storm study is given by $S o j k a$ and Schunk [1983]. Briefly, we follow a field tube of plasma as it convects through a moving neutral atmo sphere. Altitude profiles of the ion temperature and den- 


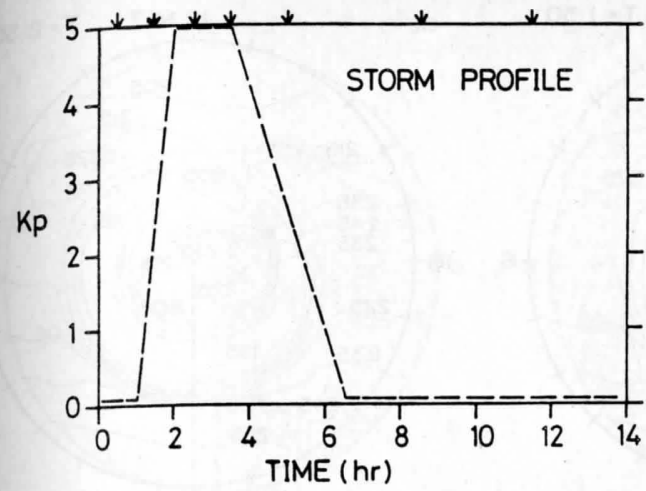

Fig. 1. Variation of $K p$ as a function of time for our idealized Fig. 1. Varic storm. The storm growth phase lasts for 1 hour, the main phase lasts for 1.5 hours, and the recovery phase lasts for 3 hours. The arrows indicate the times for which subsequent plots will be presented.

sities are obtained by solving the appropriate timedependent continuity, momentum, and energy equations, including numerous high-latitude processes. These equations are solved over the altitude range from 120 to 800 $\mathrm{km}$, with chemical equilibrium at $120 \mathrm{~km}$ and zero plasma flow at $800 \mathrm{~km}$ being the lower and upper boundary conditions, respectively. By following many field tubes of plasma we can construct a time-dependent three-dimensional model of the high-latitude ionosphere.

In our initial attempt to model the effects of a magnetospheric storm on the $F$ region ionosphere, it was essential that the resulting $F$ region trends can be clearly related to the magnetospheric storm inputs. Hence, for this theoretical study, we assumed that the two major storm inputs are (1) the changing magnetospheric convection electric field on a time scale of about an hour, and (2) the changing precipitation energy fluxes, again on a time scale of about an hour. Consequently, all other storm variations were regarded as higher-order and were neglected, except for the variation of the auroral oval size.

The storm situation we considered was a magnetospheric storm of a few hours duration. The storm perturbs the quiet time ionosphere, and then the ionosphere relaxes back to a quiet time situation. The effects of the storm are manifested in time-dependent changes to the magnetospheric convection electric field, the auroral oval size, and the auroral particle precipitation flux. The calculations were performed for winter solstice and solar maximum conditions.

Figure 1 shows the variation of the magnetic index $K p$ as a function of time for our idealized magnetospheric storm. For the first hour of the study $K p$ was held at a prestorm value of 0.07 . This was followed by a storm growth phase of one hour, during which time the $K p$ index increased linearly to a value of 5 . The storm main phase lasted 1.5 hours, after which the $K p$ index decreased linearly to its prestorm value of 0.07 . The recovery phase lasted 3 hours. The model study was then $F$ rentinued for an additional 7.5 hours in order to allow the $F$ region ionosphere sufficient time to relax back to a quiet time situation. Above the storm profile in Figure 1 are several arrows, which indicate the times at which results are displayed in subsequent figures.
Our magnetospheric convection model uses the $K p$ index to determine the cross polar cap potential drop and the asymmetry in the dawn-dusk convection cells. We associated a $K p$ of 0.07 with the quiet time cross polar cap potential drop of $20 \mathrm{kV}$ and a $K p$ of 5 with the storm main phase potential of $90 \mathrm{kV}$, and we interpolated linearly for intermediate values. Our quiet time model has two symmetric convection cells $\left(\phi_{\text {dawn }}=10 \mathrm{kV}, \phi_{\text {dusk }}=\right.$ $-10 \mathrm{kV}$ ), whereas the storm main phase model has an enhanced convection cell in the dusk sector $\left(\phi_{\text {dawn }}=15\right.$ $\mathrm{kV}, \phi_{\text {dusk }}=-75 \mathrm{kV}$ ); the convection in the dawn cell is only slightly stronger than that for the prestorm case. The asymmetry of the dusk cell was assumed to vary linearly with $K p$ from prestorm to storm main phase conditions. At latitudes equatorward of the polar cap boundary, the electrostatic potential was assumed to decrease as the inverse of the fourth power of sine colatitude. During the storm main phase the polar cap boundary expands to a radius of $16.3^{\circ}$, from a prestorm radius of $14.8^{\circ}$. The polar cap is centered a few degrees $\left(2^{\circ}\right.$ to $\left.4^{\circ}\right)$ equatorward of the magnetic pole on the midnight magnetic meridian.

The auroral precipitation energy flux is clearly stormdependent; we used the empirical results of Spiro et al [1982] to model this dependence. The energy flux displays a systematic variation with the auroral index $A e$, which was varied from a prestorm value of 65 to a main phase value of 600 . During the prestorm conditions the auroral oval is approximately subvisual with energy fluxes below 0.4 ergs $\mathrm{cm}^{-2} \mathrm{~s}^{-1} \mathrm{sr}^{-1}$, while during the main phase the energy flux reaches $1.7 \mathrm{ergs} \mathrm{cm}^{-2} \mathrm{~s}^{-1} \mathrm{sr}^{-1}$. For both cases, the precipitating auroral electrons have their highest energy fluxes in the night sector. For our calculations of auroral ionization rates, we assumed that the auroral energy spectral shape did not depend on position or time. We adopted a characteristic auroral arc spectrum with a peak energy of $4 \mathrm{keV}$ [see Knudsen et al, 1977].

\section{COMPOSITION VARIATIONS}

During the storm the composition changes due to changing production rates as well as both horizontal and vertical transport effects. A good way to show these ion composition changes is via the molecular/atomic ion transition height. Figure 2 shows contours of the molecular/ atomic ion transition height for six times during the storm study. Since our model includes both $\mathrm{NO}^{+}$and $\mathrm{O}_{2}{ }^{+}$ we have associated a mean ion mass of 23.5 AMU with the transition height. The contours are shown in the MLT-magnetic latitude quasi-inertial frame and are labeled in kilometers. Associated with each panel in Figure 2 is the corresponding elapsed time from the beginning of the study. These times are shown in Figure 1 by the first five and last arrows. Panel $T=0030$ hours corresponds to prestorm conditions, $T=0130$ hours is the growth phase, $T=0230$ hours and 0330 hours are the main phase, $T=0500$ hours is in the recovery phase and $T$ $=1130$ hours is in the poststorm period.

Prior to the onset of the storm the transition height shows a high degree of variability and UT dependence [Sojka et al, 1981a, b, c]. Panel $T=0030$ hours in Figure 2 shows the spatial variability. On the dayside, in the region where solar EUV production is highest (low latitudes near noon), the transition height is low (200-215 

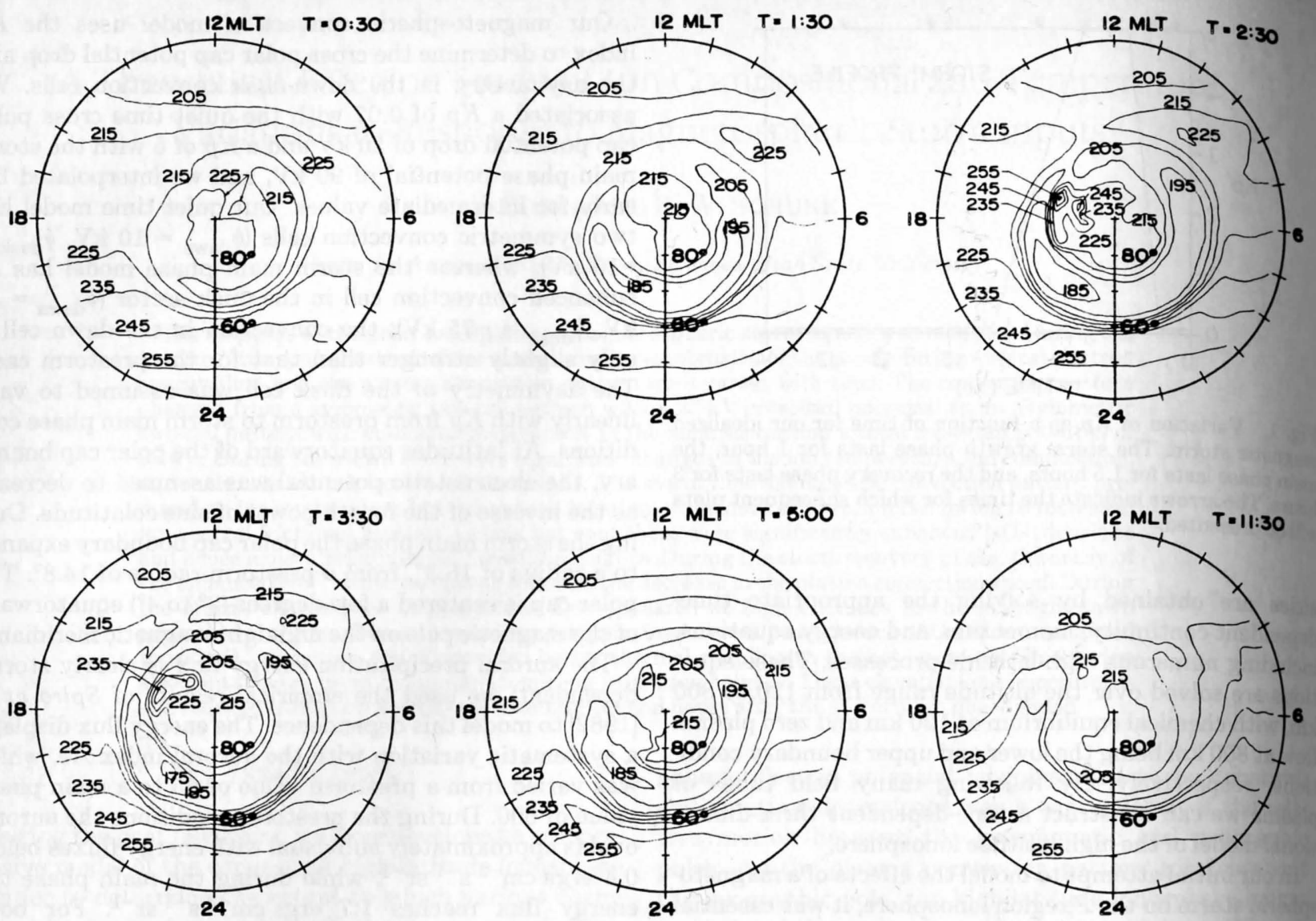

Fig. 2. Contours of the molecular/atomic ion transition height at selected times during the storm study. The transition height corresponds to a mean ion mass of 23.5. Each polar diagram corresponds to a magnetic latitudeMLT reference frame. The times used to reference each plot are in hours and minutes from the beginning of the storm study.

$\mathrm{km})$. In contrast, around midnight at low latitudes the transition height is the highest $(230$ to $260 \mathrm{~km}$ ). These high transition heights are caused by the upward induced ion drift associated with the equatorward neutral wind raising the $F$ layer. These two contrasting regions are present throughout the storm duration, and because neither depends on our model storm inputs they show little variation during the storm.

In the vicinity of the polar cap (panel $T=0030$ hours) there is a region of reduced transition height in the midnight-morning sector quiet auroral oval. Both the slightly higher production rates associated with the quiet auroral oval and the downward E x B drift component contribute to this feature. Around the noon sector auroral oval, the transition height is increased because the $\mathbf{E} \times \mathbf{B}$ drift has an upward component in this region and the production rates are lower.

In the storm growth phase (panel $T=0130$ hours) the auroral production rates increase in conjunction with increasing convection speeds and vertical transport velocities. The effect of the expanding and intensifying auroral oval is to lower the transition height in the nocturnal region because of the relative increase in $\mathrm{O}^{+}$over the molecular ions. Also, in this region the enhanced downward $\mathbf{E} \times \mathbf{B}$ drifts complement this trend, whereas on the dayside the enhanced upward E x B drifts oppose the effects of enhanced production.

During the storm main phase (panels $T=0230$ and 0330 hours), E x B transport dominates the dusk sector and auroral precipitation controls the dawn sector, and hence, these regions display marked differences in the transition height. In the dusk convection cell, where the horizontal drift speeds are greater than $2 \mathrm{~km} / \mathrm{s}$, there are also upward drifts of greater than $100 \mathrm{~m} / \mathrm{s}$ in the afternoon sector and downward drifts reaching $-100 \mathrm{~m} / \mathrm{s}$ in the evening sector. A consequence of these vertical drifts is that in the afternoon the transition height is raised from $\sim 215$ to $255 \mathrm{~km}$, while in the evening it is lowered from $\sim 215 \mathrm{~km}$ to $175 \mathrm{~km}$. Hence, over a relatively small horizonal distance the transition height varies by $80 \mathrm{~km}$ from a low value of $175 \mathrm{~km}$ to a high value of $255 \mathrm{~km}$. In the morning (dawn) sector, a wide region of lowered transition height is present, reduced from $\sim 215$ to $195 \mathrm{~km}$. This region is associated with large production rates and relatively low convection speeds.

In the recovery phase (panel $T=0500$ hours), the afternoon sector region of elevated transition heights returns to normal in conjunction with the decreasing convection speeds. However, the nocturnal region of lowered transition heights lags behind the recovering auroral precipitation by several hours. This whole region was found to exhibit an anomalously long recovery time because the storm-enhanced $\mathrm{O}^{+}$ions at high altitudes take many hours to diffuse downward as the ionosphere adjusts to prestorm conditions [see Sojka and Schunk, 1983]. As a consequence of the downward diffusing $\mathrm{O}^{+}$, the low 

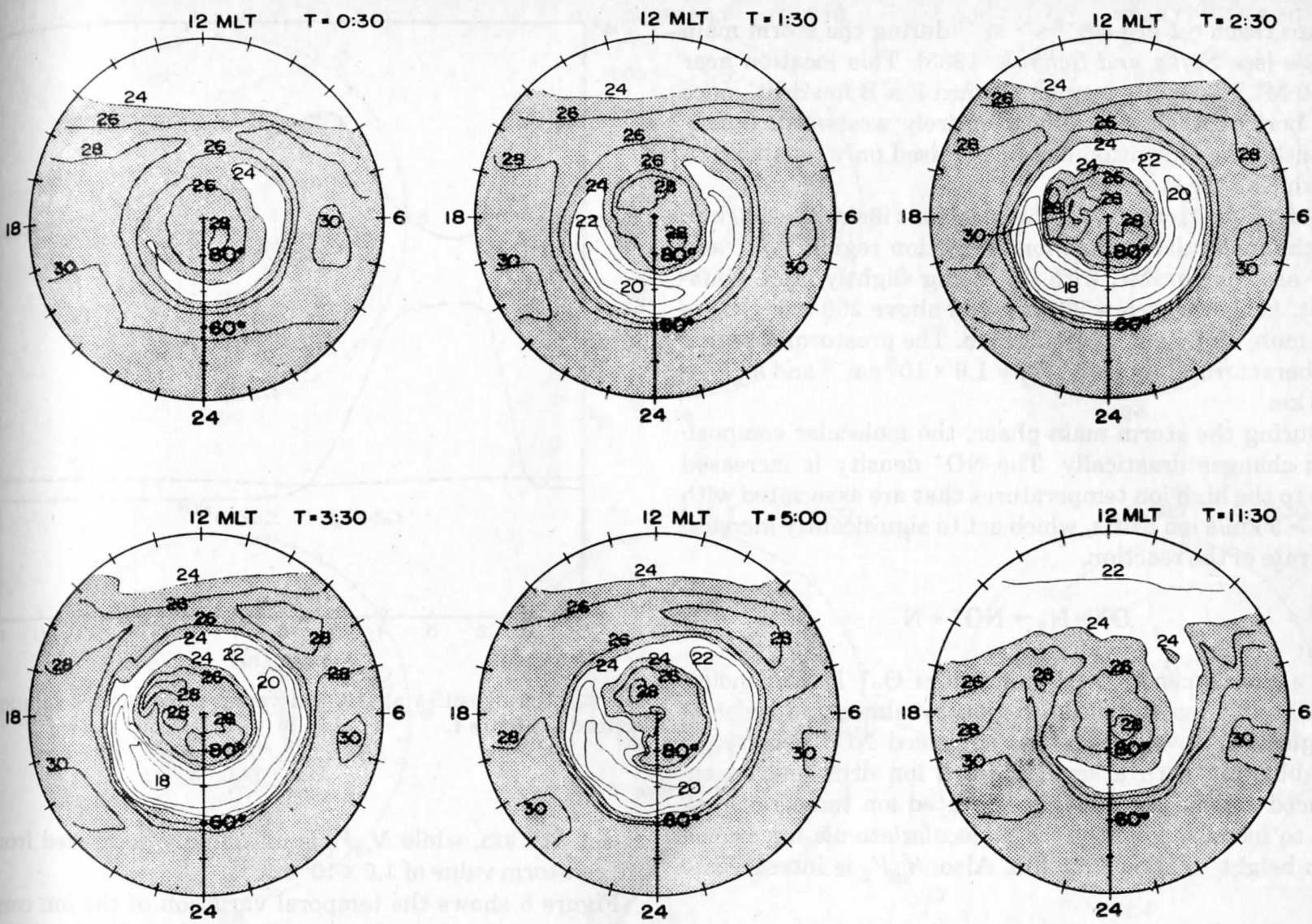

Fig. 3. Contours of the mean ion mass at $200 \mathrm{~km}$ for selected times during the storm study. The shading shows the regions where the molecular ions dominate.

transition heights are maintained long after the storm subsides.

By 1130 UT, which is well into the postrecovery period (panel $T=1130$ hours), the effects of the storm are gone. However, panel $T=1130$ hours does not look the same as the prestorm panel $T=0030$ hours. This discrepancy is quite significant, with up to a $20-\mathrm{km}$ difference in the transition height values on the dayside. The lower transition heights occur at 1130 UT and are associated with the terminator being closer to the magnetic pole at this UT. In the presence of enhanced EUV production, $\mathrm{O}^{+}$is enhanced relative to the molecular ions, and consequently, the transition height is lowered.

As a consequence of the dynamic nature of the molecular/atomic ion transition height, the composition at a given altitude will also exhibit storm associated changes. Figure 3 shows contours of the mean ion mass in AMU's at an altitude of $200 \mathrm{~km}$ for the same six times as in Figure 2. The regions where the molecular ions dominate (mean ion mass $>24$ ) are shaded. Common to all six panels in Figure 3 is a dayside region of solar EUV production where $\mathrm{O}^{+}$is dominant. This region, marked by the well-defined separation between the white and shaded regions, shows how the solar EUV terminator moves during the study, a UT effect. A second well-defined region where $\mathrm{O}^{+}$is dominant is in the auroral oval, especially in the midnight-morning sector. As already pointed out in the earlier discussion of transition heights this is a region where enhanced ion production due to auroral precipita- tion in combination with downward $\mathbf{E} \times \mathbf{~ B}$ drifts act to lower the transition height. During the storm main phase (panels $T=0230$ and $T=0330$ hours in Figure 3) this region has a mean ion mass as low as $18 \mathrm{AMU}\left(\mathrm{O}^{+}\right.$dominant), which is in contrast to the prestorm minimum of about 24 AMU (molecular ions dominant); see panel $T=$ 0030 hours. This particular region is located in the evening sector where enhanced production and downward $\mathbf{E} \mathbf{x}$ B drifts of about $100 \mathrm{~m} / \mathrm{s}$ combine to produce an $F$ region composed almost entirely of $\mathrm{O}^{+}$ions. In the afternoon sector, where $100 \mathrm{~m} / \mathrm{s}$ upward drifts are present, the mean ion mass is increased from 26 to 30 . Since this region was already dominated by molecular ions before the storm, the enhanced upward drift has little apparent effect at this altitude. During the recovery phase (panel $T=0500$ hours) the mean ion mass has a delayed recovery to its prestorm values in the noctural oval. This delay of approximately 5 hours is associated with the long time constant for the recovery of the diffusion dominated topside ionosphere.

So far we have considered only the general composition, i.e., the mean ion mass and the molecular/atomic ion transition height. However, during dynamic storm periods the molecular ion composition also changes. Figure 4 shows altitude profiles of $\mathrm{NO}^{+}, \mathrm{O}_{2}^{+}$and $\mathrm{O}^{+}$both in the prestorm period (upper panel) and in the storm main phase (lower panel) at a location of $1830 \mathrm{MLT}$ and $73.5^{\circ}$ magnetic latitude. At this location, the horizontal convection speed is in excess of $3 \mathrm{~km} / \mathrm{s}$ and the auroral energy 
fluxes reach $\sim 1 \mathrm{erg} \mathrm{cm}^{-2} \mathrm{~s}^{-1} \mathrm{sr}^{-1}$ during the storm main phase [see Sojka and Schunk, 1983]. This location near 1800 MLT has only a small upward E x B ion drift, since the horizontal flow is almost entirely westward. Consequently, the transition height is raised only by about 15 $\mathrm{km}$ during the storm.

Before the storm, $\mathrm{O}^{+}$is the dominant ion above $200 \mathrm{~km}$. In the molecular/atomic ion transition region, $\mathrm{NO}^{+}$and $\mathrm{O}_{2}{ }^{+}$are comparable, with $\mathrm{O}_{2}^{+}$being slightly more abundant. However, below $200 \mathrm{~km}$ and above $250 \mathrm{~km}, \mathrm{NO}^{+}$is the more abundant molecular ion. The prestorm $F$ region is characterized by an $N_{m} F_{2} \approx 1.6 \times 10^{5} \mathrm{~cm}^{-3}$ and $h_{m} F_{2} \approx$ $300 \mathrm{~km}$.

During the storm main phase, the molecular composition changes drastically. The $\mathrm{NO}^{+}$density is increased due to the high ion temperatures that are associated with the $\geqslant 3 \mathrm{~km} / \mathrm{s}$ ion drifts, which act to significantly increase the rate of the reaction,

$$
\mathrm{O}^{+}+\mathrm{N}_{2} \rightarrow \mathrm{NO}^{+}+\mathrm{N}
$$

As a consequence, $\mathrm{NO}^{+}$dominates $\mathrm{O}_{2}^{+}$in the molecular/atomic ion transition region by almost an order of magnitude. In addition, the enhanced $\mathrm{NO}^{+}$density, in combination with a small upward ion drift and an enhanced plasma scale height (elevated ion temperatures), act to increase slightly the molecular/atomic ion transition height to about $225 \mathrm{~km}$. Also, $h_{m} F_{2}$ is increased to

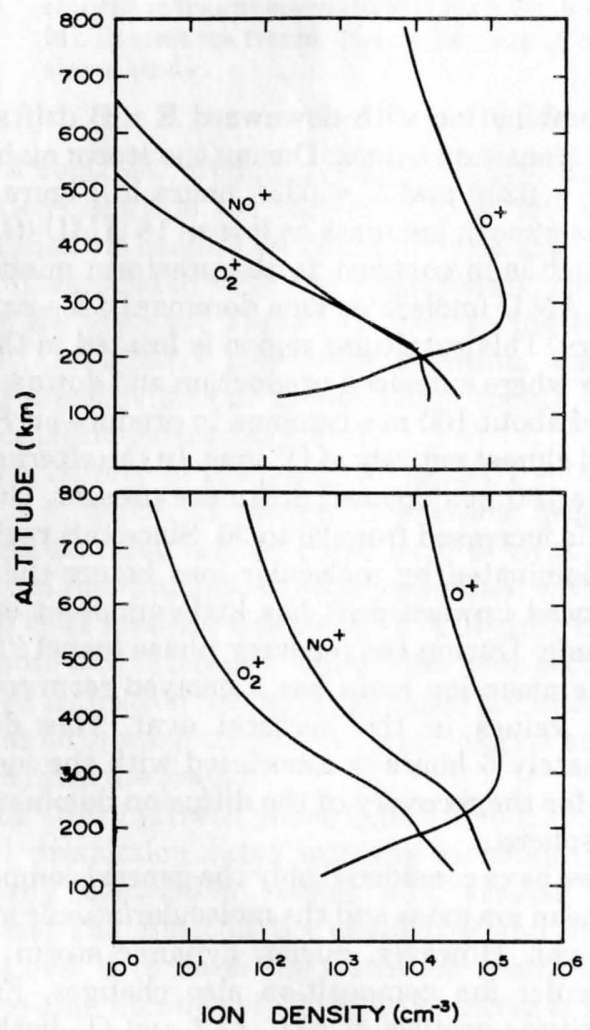

Fig. 4. Ion density profiles versus altitude at a selected location for two times during the storm study. The location is at 1830 MLT and $73.5^{\circ}$ magnetic latitude, and the times correspond to the start of the study (upper panel) and 0200 hours later (lower panel).

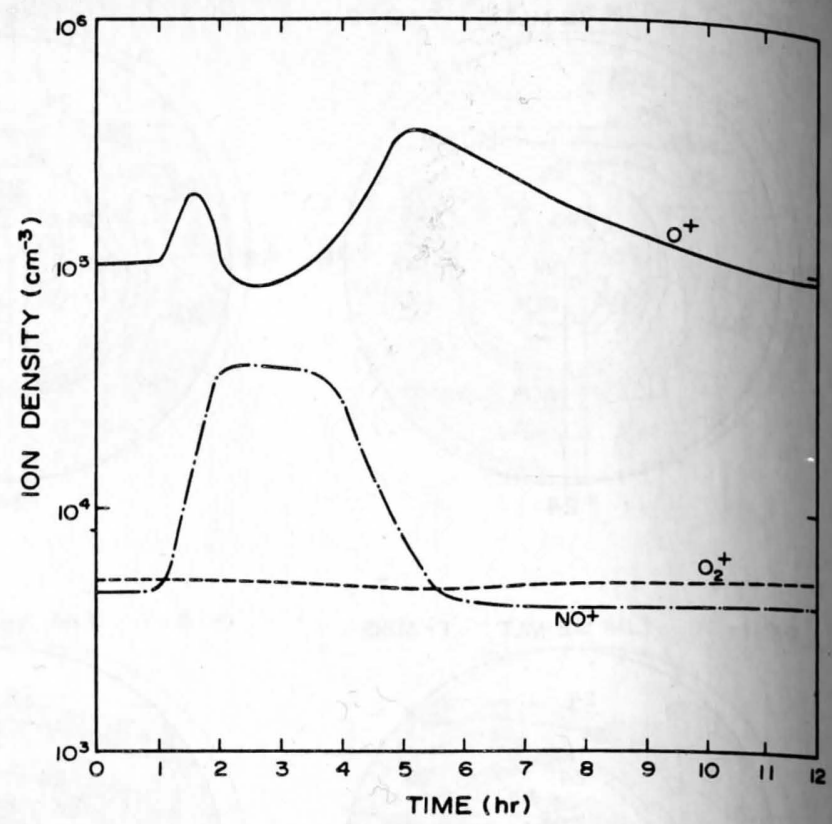

Fig. 5. Ion densities at $260 \mathrm{~km}$ versus time for the location defined in Figure 4.

about $320 \mathrm{~km}$, while $N_{m} F_{2}$ is marginally decreased from its prestorm value of $1.6 \times 10^{5} \mathrm{~cm}^{-3}$.

Figure 5 shows the temporal variation of the ion composition at the above location for an altitude of $260 \mathrm{~km}$. For each ion, the density is plotted on a logarithmic scale against time from the start of the study. The $\mathrm{O}_{2}{ }^{+}$density shows little variation, while the $\mathrm{NO}^{+}$density increases sharply during the growth phase, reaches a peak during the main phase, and then decreases to a prestorm value during the recovery phase. The $\mathrm{NO}^{+}$profile closely follows the storm profile in Figure 1. During the storm the $\mathrm{NO}^{+}$density reaches a value of $4 \times 10^{4} \mathrm{~cm}^{-3}$ from a prestorm value of $5 \times 10^{3} \mathrm{~cm}^{-3}$.

In contrast to the molecular ion behavior, the $\mathrm{O}^{+}$variation is significantly more complex (see Figure 5). Initially, the $\mathrm{O}^{+}$density increases during the growth phase. However, before the end of the growth phase the $\mathrm{O}^{+}$density starts to decrease and by the time the main phase is reached the $\mathrm{O}^{+}$density is less than the prestorm value. This behavior is the result of two processes combining to give enhanced $\mathrm{NO}^{+}$and reduced $\mathrm{O}^{+}$. At this altitude, which is below $h_{m} F_{2}$, the small upward ion drift during the storm is enough to make $\mathrm{O}^{+}$appear to decrease even though enhanced auroral production acts to increase the $\mathrm{O}^{+}$density. In addition, as the horizontal speed becomes $\gtrsim 1 \mathrm{~km} / \mathrm{s}$, ion heating leads to an enhanced reaction rate for the reaction given by equation (1), causing an $\mathrm{O}^{+} \overrightarrow{ }$ $\mathrm{NO}^{+}$conversion. During the recovery phase $(0330$ to 0530 hours), $\mathrm{NO}^{+}$returns to its prestorm density as both the reaction rate and upward drift return to their normal values. However, $\mathrm{O}^{+}$does not; initially, during the recovery phase a marked increase in $\mathrm{O}^{+}$is observed. This results both from the lowering of $h_{m} F_{2}$ and from higher $\mathrm{O}^{+}$densities being transported to this altitude. The elevated $\mathrm{O}^{+}$densities at high altitudes persist for many hours after the storm, since the diffusion time constant is 

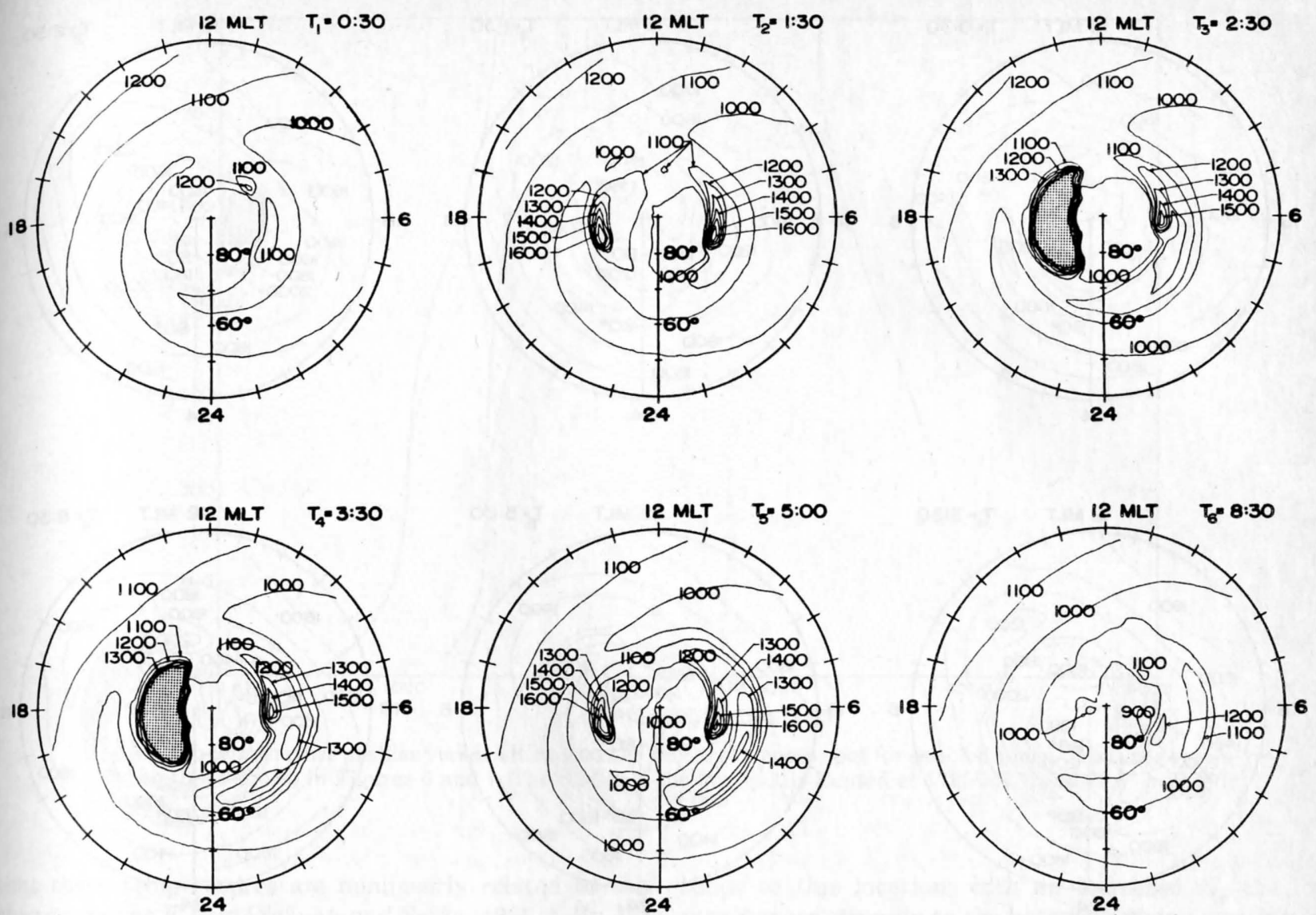

Fig. 6. Contours of the ion temperature $\left({ }^{\circ} \mathrm{K}\right)$ at $340 \mathrm{~km}$ for selected times during the storm study. The shaded areas correspond to regions of ion temperature greater than $1600^{\circ} \mathrm{K}$.

several hours. The $\mathrm{O}^{+}$density in Figure 5 does not return to its prestorm level until about 1100 hours.

\section{ION TEMPERATURE VARIATIONS}

From our previous model studies of the $F$ region ion temperature under nonstorm conditions [Schunk and Sojka, 1982a, b], it is expected that the ion temperature will show distinct spatial and temporal variations under dynamic storm conditions. In particular, the high dusk sector electric fields used in our storm model are expected to produce an ion temperature hot spot at high latitudes. Figure 6 shows contours of the ion temperature at an altitude of $340 \mathrm{~km}$ at six times during the storm study. The six times correspond to the times indicated in Figure 1 by the first six arrows. Except for the last time, these times are also the same as used for the previous discussion of ion composition. Also, the temperatures are presented in the same frame as for Figures 2 and 3, namely the quasi-inertial MLT-magnetic latitude frame.

For the prestorm conditions (panel $T=0030$ hours in Figure 6), the ion temperature is relatively uniform, lying between 1000 and $1200^{\circ} \mathrm{K}$. During the growth phase (panel $T=0130$ hours), the ion temperature in the dawn and dusk cells, where the electric field is increasing, becomes elevated owing to the localized heating. The temperature increases from 1100 to $1600^{\circ} \mathrm{K}$; this increase is initially symmetric for the two cells since the dawn/ dusk asymmetry evolves during the growth phase. Panels
$T=0230$ and 0330 hours show the main phase ion temperatures at a time when the convection velocity asymmetry is fully developed. In the center of the enhanced dusk cell, where horizontal velocities between 2 and $4 \mathrm{~km} / \mathrm{s}$ are present, the ion temperature reaches a peak value of $3700^{\circ} \mathrm{K}$. This "hot spot" is readily identified during the main phase by the shading. Outside this region the ion temperature remains below $1600^{\circ} \mathrm{K}$ at 340 $\mathrm{km}$. By $T=0330$ hours, at the end of the main phase, a secondary dawn region of higher ion temperatures begins to appear. This region corresponds to the auroral oval on the nightside where the densities are gradually building up at and above the $F_{2}$ peak.

During the recovery phase (panel $T=0500$ hours), the dusk hot spot disappears, since the electric field decreases. However, the more equatorward high temperature region in the dawn sector shows a further $100^{\circ} \mathrm{K}$ increase in temperature. In this region the topside ionosphere does not reach its peak density until about 5 hours after the storm main phase. Since these topside higher densities give better thermal coupling to the hot electrons, this region reaches its highest ion temperatures $\left(\gtrsim 1400^{\circ} \mathrm{K}\right.$ ) several hours after the storm main phase. Even well into the poststorm period (panel $T=0830$ hours), this equatorward region of elevated ion temperatures is present in the dawn sector. At other locations the storm effects have disappeared, and the remaining differences relative to the prestorm temperatures (panel $T=$ 0030 hours), are due to the UT-dependent nature of the $F$ region. 

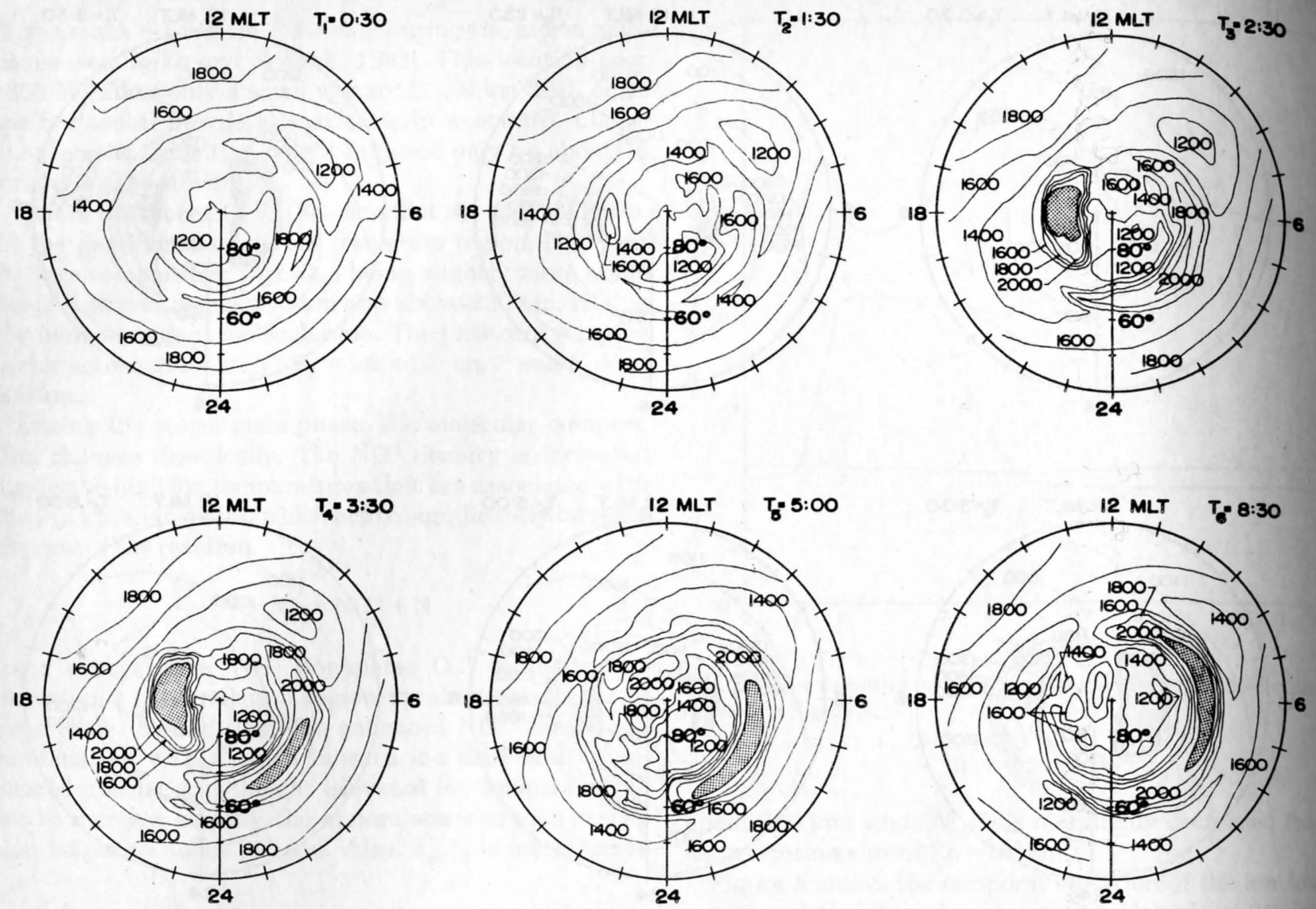

Fig. 7. Contours of the ion temperature $\left({ }^{\circ} \mathrm{K}\right)$ at $600 \mathrm{~km}$ for selected times during the storm study. The shaded areas correspond to regions of ion temperature greater than $2200^{\circ} \mathrm{K}$.

Figure 7 shows contours of the ion temperature at an altitude of $600 \mathrm{~km}$ for the same times as in Figure 6. At high altitudes the ion density structure is more complicated owing to the effects of horizontal transport [see Sojka and Schunk, 1983], which leads to more complicated temperature variations. The temperatures are higher and have a wider dynamic range; at $T=0030$ hours (prestorm) the ion temperature variation is from 1200 to $1800^{\circ} \mathrm{K}$, while at $340 \mathrm{~km}$ the prestorm variation was from 1000 to $1200^{\circ} \mathrm{K}$ (see Figure 6). During the growth phase (panel $T=0130$ hours in Figure 7), the elevated temperatures in the dawn sector observed at $340 \mathrm{~km}$ in regions of increasing $\mathbf{E} \times \mathbf{B}$ drift are not discernable at $600 \mathrm{~km}$. The main phase "hot spot" in the dusk sector is present; however, at this altitude the peak ion temperature is about $3000^{\circ} \mathrm{K}$ compared to $3700^{\circ} \mathrm{K}$ at $340 \mathrm{~km}$ (panel $T=0230$ and $T=0330$ hours in Figure 7).

In the dawn sector, the main phase, recovery phase, and poststorm phase are all dominated by the equatorward region of elevated ion temperatures that are associated with the topside $N_{e}$ increase after the storm main phase. This region, indicated by the shading in panels $T=$ $0330, T=0500$ and $T=0830$ hours, has temperatures between 2200 and $2600^{\circ} \mathrm{K}$. As late as 5 hours after the storm main phase, this region of elevated ion temperatures covers a wide area of the dawn sector auroral oval (0200 to $1100 \mathrm{MLT}$ and $60^{\circ}$ to $70^{\circ}$ magnetic latitude). These temperatures are still between 400 and $1000^{\circ} \mathrm{K}$ hotter than the prestorm temperatures (compare 0830 and 0030 panels in Figure 7), while at this time the ion temperatures at $340 \mathrm{~km}$ had returned to within about $100^{\circ}$ of their prestorm values.

Clearly, the ion temperatures at the two altitudes described above behave in different ways, with the temperature at the higher altitude being very sensitive to the delayed reaction of the topside ionosphere to the storm. At this point it is instructive to show how the altitude profile of the ion temperature varies with time. Figure 8 shows six altitude profiles of $T\left(\mathrm{O}^{+}\right)$for a location at the center of the dusk "hot spot." This location corresponds to $1730 \mathrm{MLT}$ and $73.5^{\circ}$ magnetic latitude. The six times are the same as those used in Figures 7 and 8 , and each curve is labeled in chronological order from $T_{1}$ to $T_{6}$. In Figure 8, the profile labeled $T_{1}$ corresponds to prestorm conditions. Below about $350 \mathrm{~km}$ the ion temperature is strongly coupled to the neutral temperature, whereas above this altitude the ion temperature increases as the ions couple more strongly to the hot electrons. During the initial part of the growth phase $\left(T_{2}\right)$, the low altitude ion temperature increases due to ion-neutral frictional heating and the increased $E$ field. During the storm main phase $\left(T_{3}\right.$ and $T_{4}$ ), this frictional heating reaches its peak when the $E$ field maximizes, with the result that $T_{2}>$ $4000^{\circ} \mathrm{K}$ at low altitudes. At this time the ion temperature decreases with increasing altitude. This uncharacteristic temperature profile is associated with the high latitude hot spot [see Schunk and Sojka, 1982b]. As the storm recovers $\left(T_{5}\right)$, the low-altitude ion temperatures decrease as the $E$ field decreases. In the hot spot region, where elevated ion temperatures are present, it should be noted 


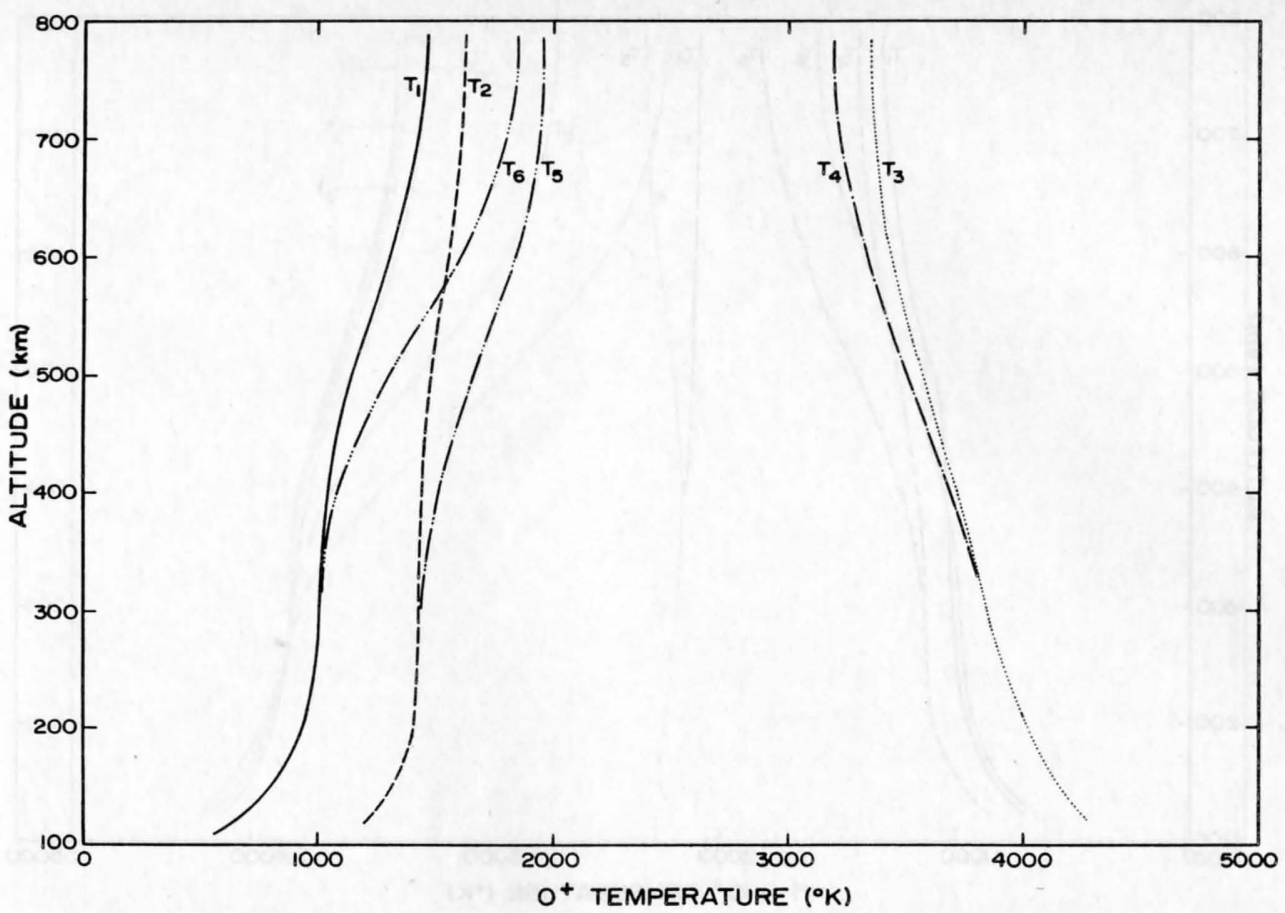

Fig. 8. Ion temperature profiles versus altitude at the center of the hot spot for selected times. The times correspond to those shown in Figures 6 and 7. The center of the hot spot is located at $1730 \mathrm{MLT}$ and $73.5^{\circ}$ magnetic latitude.

that these temperatures are nonlinearly related to the changes in the $E$ field [Schunk and Sojka, 1982b]. By $T_{6}$, the poststorm period, the ion temperatures at low altitudes have returned to their prestorm values (compare with $T_{1}$ ), but elevated ion temperatures are still present at high altitudes owing to the persistence of stormenhanced ion densities at these altitudes.

Figure 9 shows the storm variation of the ion temperature profile at the edge of the hot spot. This location is at $1830 \mathrm{MLT}$ and $76.5^{\circ}$ magnetic latitude, which is only one hour later in MLT and $3^{\circ}$ poleward of the hot spot center of Figure 8. The comparison of Figures 9 and 8 shows that at the corresponding times during the storm the two locations behave similarly. However the ion temperatures at the edge of the hot spot are not as high as those at the center. During the main phase $\left(T_{3}\right.$ and $\left.T_{4}\right)$, Figure 9 shows an altitude profile that displays an almost constant temperature of $2200^{\circ} \mathrm{K}$. This profile is markedly different from the corresponding temperature profile at the center of the hot spot, which decreases with altitude from $4000^{\circ} \mathrm{K}$ to about $3300^{\circ} \mathrm{K}$ at $800 \mathrm{~km}$.

In Figure 10 ion temperature profiles are shown at a location of $0630 \mathrm{MLT}$ and $61.5^{\circ}$ magnetic latitude for the same six times used in Figures 6-9. This region is associated with delayed high-altitude storm temperature enhancements (see panels $T=0500$ and $T=0830$ hours, Figure 7). Also, this region is in the weak dawn convection cell and equatorward of the strongest precipitation region. Consequently, below $300 \mathrm{~km}$, the ion temperature remains coupled to the neutral temperature, which is storm independent in our model. At high altitudes the recovery and poststorm profiles, $T_{5}$ and $T_{6}$, show marked ion temperature increases. These increases are directly related to the horizontal transport of high-density $\mathrm{O}^{+}$flux tubes to this location; with an increased $N_{e}$ the ions couple more strongly to the hotter electrons, causing the ion temperature increase. Although this low convection cell region is in darkness and is an area of weak precipitation after the storm, the high densities persist for many hours owing to the long time constant (several hours) for downward diffusion of the storm-enhanced topside $\mathrm{O}^{+}$ densities. A similar dusk sector delayed ion temperature enhancement does not occur because the high horizontal transport velocities coupled with the large downward $\mathbf{E} \mathbf{x}$ B ion drifts prevent a high density topside from being formed [see Sojka and Schunk, 1983].

\section{SUMmary AND Discussion}

We modeled the response of the high-latitude $F$ region to magnetospheric storm inputs. During the "storm," the spatial extent of the auroral oval, the intensity of the precipitating auroral electron energy flux, and the plasma convection pattern were varied with time. Temporal variations in the precipitating electron energy flux produced variations in the ionization rates, and hence, ion densities. Variations in the plasma convection pattern produced changes in both the vertical and horizontal electrodynamic drift components. A change in the vertical drift affects $N_{m} F_{2}, h_{m} F_{2}$, and the ion composition, while a change in the horizontal convection speed alters the time a plasma flux tube spends in a given region and produces a change in the ion temperature via ion-neutral frictional heating. In turn, a change in the ion temperature affects the ion chemical reaction rates and the topside plasma scale height. In general, the various high-latitude processes compete in a complicated manner.

One of the more important results that was noted in our 


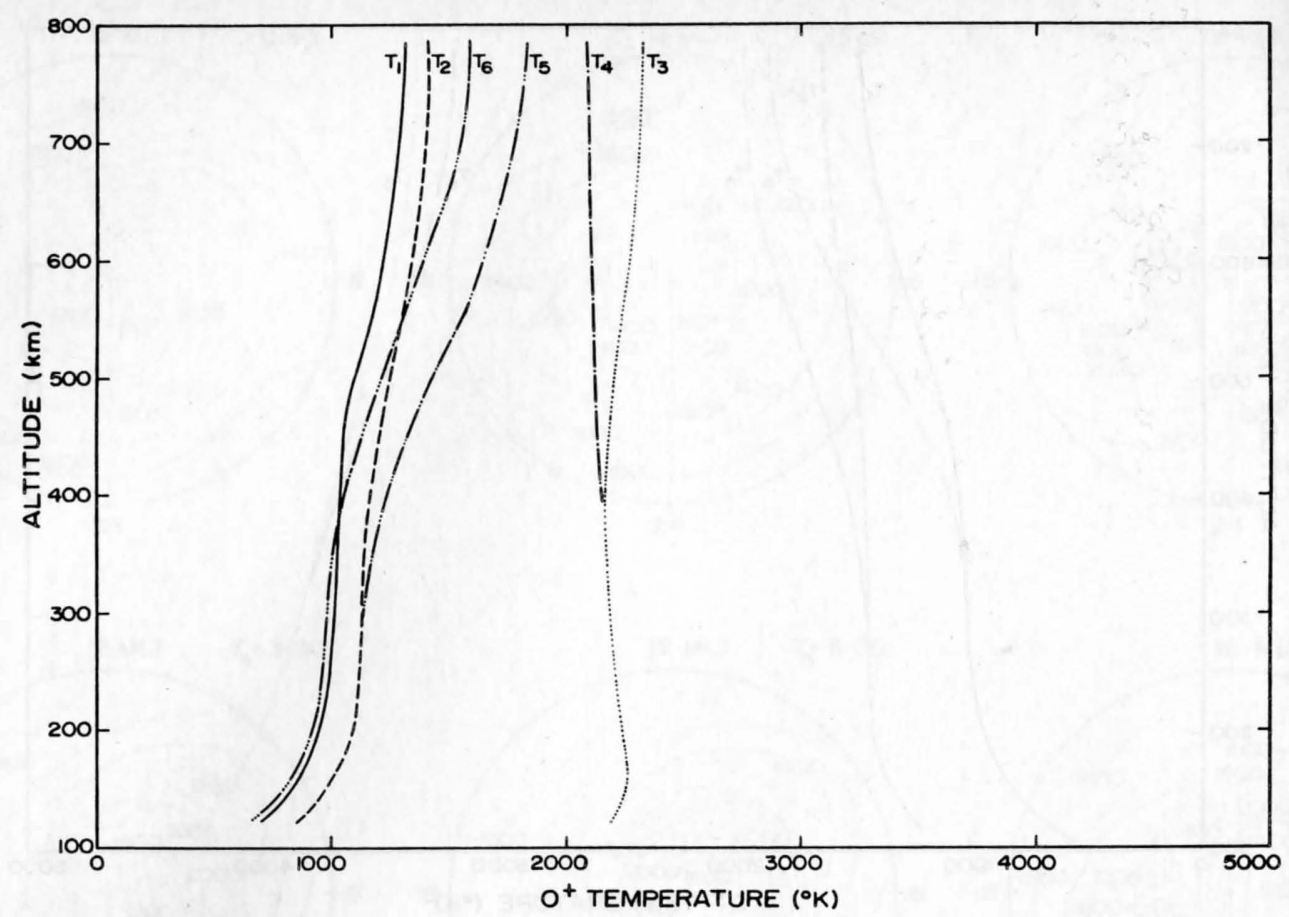

Fig. 9. Ion temperature profiles versus altitude at the edge of the hot spot for selected times. The location is $1830 \mathrm{MLT}$ and $76.5^{\circ}$ magnetic latitude.

first storm paper [Sojka and Schunk, 1983] was that the ionospheric response time is a strong function of altitude. At low altitudes $(<200 \mathrm{~km})$, photochemical processes dominate and the time constant for electron density variations is of the order of minutes. As a consequence the temporal changes in the density, during the storm, track the changes in the ionization production rates, and the spatial boundaries of the different production sources are clearly visible. However, as altitude increases, the importance of both horizontal plasma convection and fieldaligned plasma diffusion increases. As transport processes become more important, the ionosphere responds more slowly to auroral ionization sources. Consequently, near and above the $F$ region peak, the electron density variations are not correlated with the morphology of the storm auroral precipitation or the temporal variation of the storm electric field pattern. The upper $F$ region does not feel the full effect of the storm until after the storm activity ceases.

In this paper we presented the response of the $F$ region ion composition and temperature to the same changes in magnetospheric storm inputs used in the study described above. During the storm growth phase, the auroral oval expanded, the precipitating electron energy flux increased, and the magnetospheric convection pattern changed from a symmetric two-cell pattern with a $20-\mathrm{kV}$ cross-tail potential to an asymmetric two-cell pattern with a total cross-tail potential of $90 \mathrm{kV}$. The asymmetric convection pattern contained significantly enhanced plasma flow in the dusk sector and only slightly enhanced flow in the dawn sector. This asymmetric pattern produced vertical $\mathbf{E} \times \mathbf{B}$ drifts that were upward on the dayside and downward on the nightside.

Before the storm the ion temperature was relatively uniform over the entire high-latitude region at altitudes above the $F_{2}$ peak $\left(T_{i} \sim 1000-1200^{\circ} \mathrm{K}\right)$. At the beginning of the storm growth phase, two relatively weak ion temperature hot spots appeared at the centers of the convection cells as the electric field increased. As the storm buildup continued, the ion temperature in the dusk hot spot continued to increase, as did the size of the hot spot, while the ion temperature enhancement in the dawn hot spot remained small. During the storm main phase, the ion temperature at the center of the dusk hot spot was greater than $4000^{\circ} \mathrm{K}$ at low altitudes. During the recovery phase, the ion temperature decreased in the hot spot as the convection speed in the dusk cell decreased. These ion temperature variations were simply due to the variation in the ion-neutral frictional heating rate, and the size and shape of the hot spots were determined by the storm convection pattern.

During the storm, elevated ion temperatures also appeared at high altitudes in the midnight-dawn auroral oval region. These elevated ion temperatures were a consequence of the storm-enhanced topside $\mathrm{O}^{+}$densities, which provided better thermal coupling to the hot electrons. As noted in our previous paper [Sojka and Schunk, 1983], these enhanced topside $\mathrm{O}^{+}$densities persisted for several hours after the end of the storm main phase. Likewise, the elevated ion temperatures also persisted, and at $800 \mathrm{~km}$ there were regions where $T_{i}$ reached a peak of about $2600^{\circ} \mathrm{K}$ five hours after the storm main phase ended. This temperature is more than $1000^{\circ} \mathrm{K}$ hotter than the prestorm temperatures in these regions.

The ion composition and the molecular/atomic ion transition height also displayed marked variations during the storm. In general, the variations were related to changes in the intensity of the auroral precipitation, the magnitude of the $\mathbf{E} \times \mathbf{B}$ drift velocity, and the magnitude and direction of the induced vertical ion drift. 


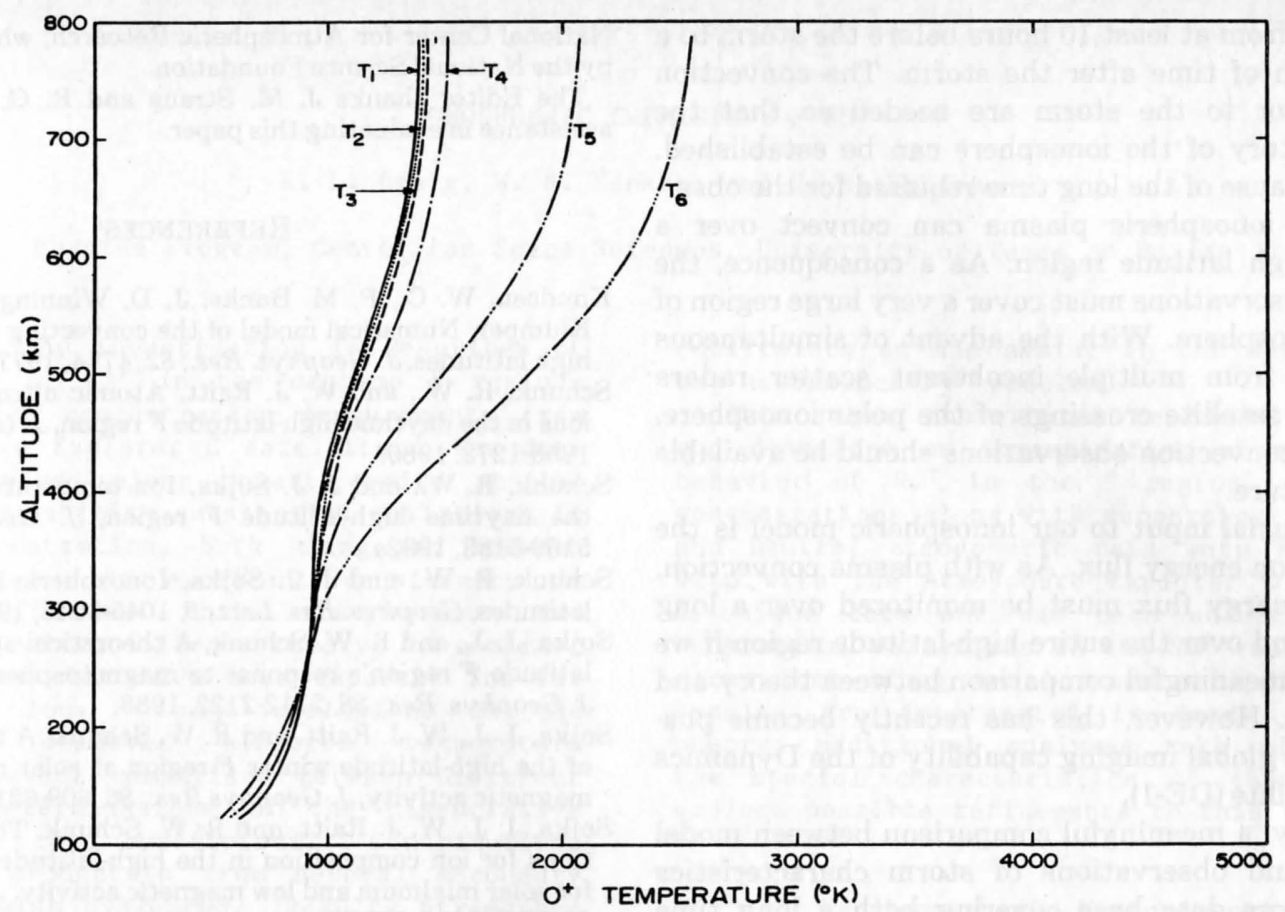

Fig. 10. Ion temperature profiles versus altitude in the morning sector for selected times. The location is 0630 MLT and $61.5^{\circ}$ magnetic latitude.

In the dusk convection cell, there was a significant increase in the $\mathrm{NO}^{+}$density and hence in the molecular/atomic ion transition height during the storm. These increases resulted primarily from the elevated ion temperatures, which acted to increase the rate of the reaction $\mathrm{O}^{+}+\mathrm{N}_{2} \rightarrow \mathrm{NO}^{+}+\mathrm{N}$. During the storm recovery phase, the decay of the enhanced $\mathrm{NO}^{+}$densities and the decrease in the molecular/atomic ion transition height closely followed the decrease in the convection speed.

In the midnight-dawn auroral oval region, there was a significant increase in the $\mathrm{O}^{+}$density and a corresponding decrease in the molecular/atomic ion transition height during the storm. For our storm convection model, the electric fields remain small in the dawn sector, but auroral precipitation increases. The increased precipitation produced enhanced $\mathrm{O}^{+}$densities that, in combination with a downward $\mathbf{E} \times \mathbf{B}$ drift component, acted to lower the molecular/atomic ion transition height. These lowered transition heights persisted for many hours after the storm owing to the downward diffusion of the stormenhanced $\mathrm{O}^{+}$densities at high altitudes, as discussed above.

Although we take account of thermospheric winds in our modeling [cf. Sojka et al, 1981c], for this study the adopted wind pattern did not vary in response to the changing magnetospheric inputs. The enhanced convection associated with a geomagnetic storm will provide both momentum and energy sources for the thermosphere. Momentum forcing will act to drive the thermosphere in the plasma direction, which will tend to reduce the ion-neutral frictional heating rate and hence the ion temperature. Joule heating produces neutral composition changes, which affect ion-neutral chemical reaction rates and hence ion densities. However, when the magnetospheric inputs are varied, the time constant for thermo- spheric changes is much greater than the time constant for ionospheric changes. Typically, the thermosphere responds with a time constant of 1-4 hours, depending on the ionospheric conditions. For the situation we considered, most of the magnetospheric variations occurred within 3 hours and $N_{m} F_{2} \sim 10^{5} \mathrm{~cm}^{-3}$. Under these conditions, a significant thermospheric response is not expected.

In this and our previous storm paper [Sojka and Schunk, 1983], we have shown that the ionospheric density, composition, and temperature display a marked variation with changes in the magnetospheric storm inputs. Since magnetic storms and substorms are common, it would appear to be a relatively straightforward task to compare model predictions with observations, and thereby determine the validity of our storm model. Unfortunately, our storm studies have indicated that the spatial and temporal changes in the ionospheric properties are not simply related to the magnetospheric storm inputs. Consequently, a meaningful comparison between model predictions and observations for storm conditions requires data obtained simultaneously from several ground-based sites and satellites, not only of the $F$ region parameters as a function of time and position but also of the magnetospheric and thermospheric inputs. At the present time the existing data base is far too incomplete to warrant a comparison between model predictions and observations of storm characteristics. However, our storm studies have helped define the required measurements for a meaningful comparison between theory and observations, and these are described below.

One of the most important requirements for a meaningful comparison is that the various inputs and outputs be monitored for many hours. For example, the plasma convection velocities must be measured for a period of time 
that extends from at least 10 hours before the storm to a similar length of time after the storm. The convection velocities prior to the storm are needed so that the prestorm history of the ionosphere can be established. However, because of the long time required for the observations, the ionospheric plasma can convect over a significant high latitude region. As a consequence, the convection observations must cover a very large region of the polar ionosphere. With the advent of simultaneous observations from multiple incoherent scatter radars coupled with satellite crossings of the polar ionosphere, the required convection observations should be available in the near future.

Another crucial input to our ionospheric model is the auroral electron energy flux. As with plasma convection, the auroral energy flux must be monitored over a long time period and over the entire high-latitude region if we are to have a meaningful comparison between theory and measurement. However, this has recently become possible with the global imaging capability of the Dynamics Explorer satellite (DE-1).

In summary, a meaningful comparison between model predictions and observations of storm characteristics requires a large data base covering both a long time period ( 24 hours) and a large segment of the polar ionosphere. The data base needs to contain both magnetospheric and thermospheric inputs, such as auroral electron energy fluxes, plasma convection velocities, and thermospheric winds, as well as the ionospheric densities, composition, and temperatures, which are the model outputs. As a first step in this direction, we are beginning collaborative studies with the incoherent scatter radar community through the MITHRAS program. We are also initiating contacts with DE scientists in an effort to obtain the required complementary satellite data. However, at this time it is difficult to predict how long it will take to establish the required data base for a "typical" storm.

Acknowledgements. This research was supported by NASA grant NAGW-77 and NSF grant ATM-8217138 to Utah State University. The computer modeling effort was supported by the National Center for Atmospheric Research, which is sponsored
by the National Science Foundation.

The Editor thanks J. M. Straus and R. G. Roble for their assistance in evaluating this paper.

\section{REFERENCES}

Knudsen, W. C., P. M. Banks, J. D. Winningham, and D. M. Klumpar, Numerical model of the convecting $F_{2}$ ionosphere at high latitudes, J. Geophys. Res., 82, 4784, 1977.

Schunk, R. W., and W. J. Raitt, Atomic nitrogen and oxygen ions in the daytime high-latitude $F$ region, J. Geophys. Res., 85 , 1255-1272, 1980.

Schunk, R. W., and J. J. Sojka, Ion temperature variations in the daytime high-latitude $F$ region, J. Geophys. Res., 87, 5169-5183, 1982a.

Schunk, R. W., and J. J. Sojka, Ionospheric hot spot at high latitudes, Geophys. Res. Lett., 9, 1045-1048, $1982 b$.

Sojka, J. J., and R. W. Schunk, A theoretical study of the highlatitude $F$ region's response to magnetospheric storm inputs, J. Geophys. Res., 88, 2112-2122, 1983.

Sojka, J. J., W. J. Raitt, and R. W. Schunk, A theoretical study of the high-latitude winter $F$ region at solar minimum for low magnetic activity, J. Geophys Res., 86, 609-621, $1981 a$.

Sojka, J. J., W. J. Raitt, and R. W. Schunk, Theoretical predic tions for ion composition in the high-latitude winter $F$ region for solar minimum and low magnetic activity, J. Geophys. Res., 86, 2206-2216, $1981 b$.

Sojka, J. J., W. J. Raitt, and R. W. Schunk, Plasma density features associated with strong convection in the winter highlatitude $F$ region, $J$. Geophys. Res., 86, 6908-6916, 1981c.

Sojka, J. J., R. W. Schunk, and W. J. Raitt, Seasonal variations of the high-latitude $F$ region for strong convection, $J$. Geophys. Res., 87, 187-198, 1982.

Spiro, R. W., P. H. Reiff, and L. J. Maher, Precipitating electron energy flux and auroral zone conductances: An empirical model, J. Geophys. Res., 87, 8215-8227, 1982.

R. W. Schunk and J. J. Sojka, Center for Atmospheric and Space Sciences, Utah State University, UMC 34, Logan, UT 84322.
(Received October 11, 1983; revised January 9,1984 ; accepted January 10, 1984.) 